Bull. Mater. Sci., Vol. 6, No. 6, December 1984, pp. 1041-1046. (C) Printed in India.

\title{
Some aspects of dislocation-precipitate interaction in under-aged aluminium-germanium alloy
}

\author{
KISHORE \\ Department of Metallurgy, Indian Institute of Science, Bangalore 560012, India \\ MS received 6 September 1982; revised 13 December 1983
}

\begin{abstract}
A bstract. The glide dislocation-precipitate interaction in under-aged alloy is investigated by microscopy and low-temperature deformation techniques. Slip-line features of room temperature deformed samples were observed by optical microscopy. From tensile tests at various temperatures the variation of flow stress with $T^{2 / 3}$ was established. Comparing the present results with those obtained on the peak-hardened condition of the same alloy it is concluded that moving dislocation shear through the small rod-shaped germanium precipitates.
\end{abstract}

Keywords. Under-aged; dislocation-precipitate interaction; slip lines; flow stress.

\section{Introduction}

The interaction between glide dislocations and precipitate particles has been studied in detail in many age-hardenable alloy systems (Nicholson and Nutting 1961; Kelly 1963; Lutzering and Weissman 1970; Raynor and Silcock 1970; Nourbakhsh and Nutting 1980). From mechanical property studies coupled with microscopy, it is possible to arrive at the likely interaction between moving dislocations and precipitate particles. While efforts are not wanting in understanding the dislocation precipitate interaction in peak-aged and over-aged states, the partially-aged condition has received hardly any attention. The purpose of the present work is to study the dislocation-precipitate interaction in under-aged aluminium- $2 \%$ germanium alloy using microscopy and mechanical deformation techniques.

\section{Experimental}

Weighed quantities of super-pure aluminium and germanium were melted together in an argon atmosphere in a resistance furnace and cast in a graphite-lined metal mould. The Ge content was $1.98 \%$ by weight. The cast ingot was lightly worked by hammering before annealing at $400^{\circ} \mathrm{C}$ for $48 \mathrm{hr}$. The homogenised rod was reduced to a $1 \mathrm{~mm}$ thick strip by cold-rolling coupled with intermediate annealing treatment. Tensile and hardness samples were cut from the rolled strip and electropolished after mechanical polishing. They were solutionised at $450^{\circ} \mathrm{C}$ for $2 \mathrm{hr}$ and quenched into ice-water mixture maintained close to $0^{\circ} \mathrm{C}$. Thermostatically-controlled paraffin oil bath, maintained at $165^{\circ} \mathrm{C}$, was used for ageing the samples. Hardness variation with ageing time was determined using a Vicker's unit. From such a data it was possible to establish the peak-hardened condition. In the present experiment as the peak hardness occurred 
at around $70 \mathrm{hr}$, the tensile test specimens were aged for $18 \mathrm{hr}$ to have the microstructure corresponding to the under-aged condition.

The partially-aged test specimens with a gauge length of $20 \mathrm{~mm}$ were pulled in a modified Hounsfield tensometer (Prasad et al 1969) at a strain rate of about $10^{-3} \mathrm{sec}^{-1}$ at temperatures varying between 77 and $420^{\circ} \mathrm{K}$. From the load-elongation plot, the flow stress was determined. The tensile-deformed samples were viewed under a light microscope for slip-line features. Using the window technique and an electrolyte of $90 / 10$ acetic acid/perchloric acid mixture maintained at $-15^{\circ} \mathrm{C}$, electron transparent thin specimen in aged condition was prepared for viewing under a Philips 301 microscope. Electrolytic thinning was achieved by applying a voltage of $18 \mathrm{~V}$ between the electrode and the specimen.

\section{Results and discussion}

Figure 1 shows the variation in Vickers hardness number as a function of time of ageing at $165^{\circ} \mathrm{C}$. The data points follow the typical trend seen in any age-hardenable alloy system, namely, an increase of hardness as ageing occurs, a peak followed by a decrease. The peak corresponding to an optimum dispersion of precipitates (Mott and Nabarro 1940) occurs around $70 \mathrm{hr}$ as mentioned earlier. Figure 2, a TE micrograph, depicts the appearance and distribution of precipitates in the under-aged condition. Small and dense rod-shaped Ge precipitates can be clearly seen in the photomicrograph. The inter-particle spacing and the size of the rods in the under-aged sample are smaller (figure 2) compared to the peak-aged condition (figure 3).

The slip-line pattern of partially-aged and room temperature-deformed sample is shown in figure 4. They are straight running, continuous and thin. Slip-line features resemble the pattern obtained for peak-aged state (Kishore and Vasu 1978). It is known that slip bands give reliable information about the mechanism of plastic deformation of the materials (Seeger 1963). The slip-line appearance could change with a change in the type of obstacle present in the matrix. When small coherent particles are present, the dislocation can easily shear the particle aggregates and the appearances of the line in such cases are only slightly different from those obtained for the pure metal or solid

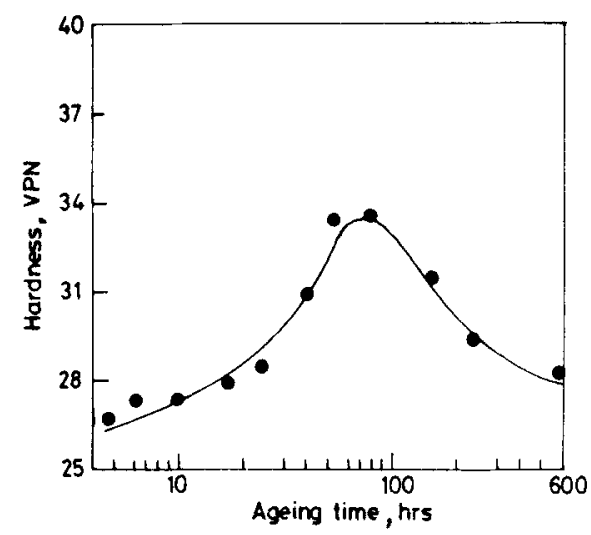

Figure 1. Hardness variation with time during ageing at $165^{\circ} \mathrm{C}\left(T_{q}=450^{\circ} \mathrm{C}\right)$. 


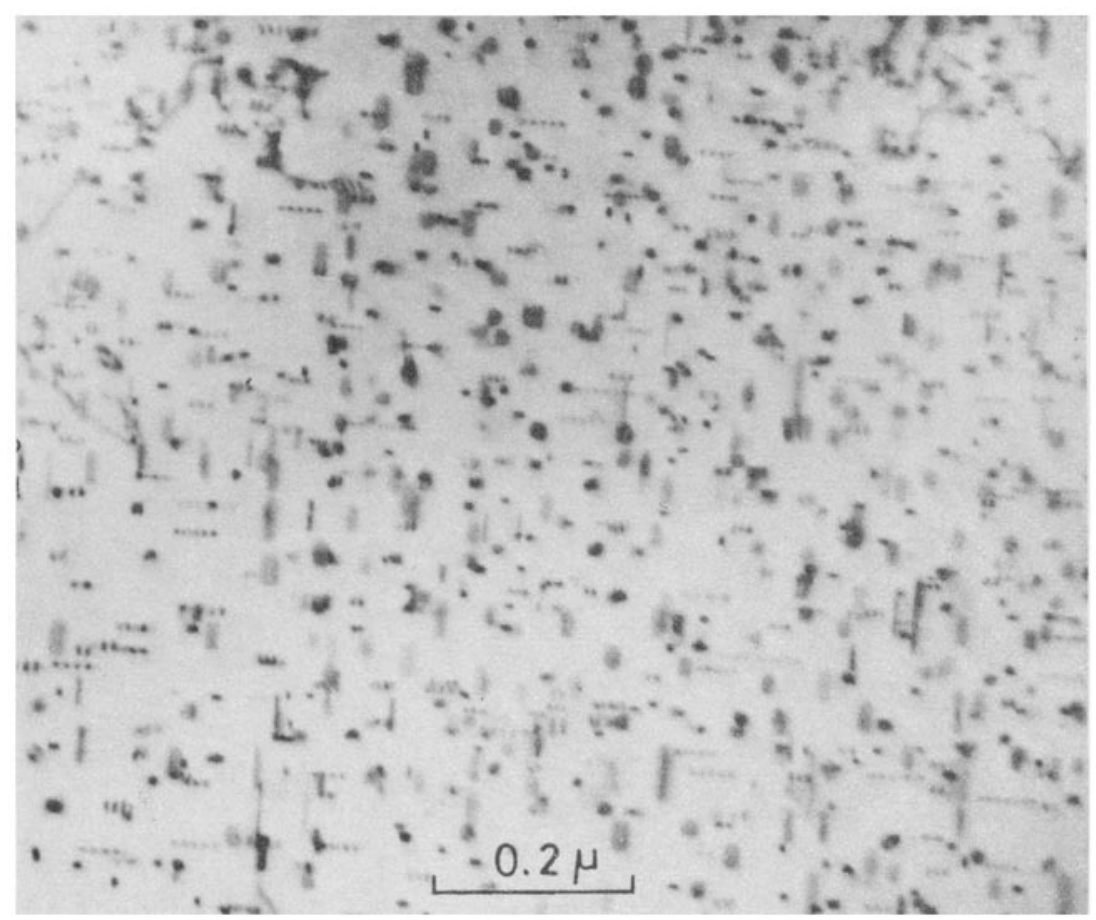

Figure 2. Electron micrograph of partially-aged sample showing small and dense rodshaped precipitates $\left(T_{q}=450^{\circ} \mathrm{C}, T_{a}=165^{\circ} \mathrm{C}, t_{a}=18 \mathrm{hr}\right)$.

solution (Greetham and Honeycombe 1960-61; Silcock 1960; Thomas and Nutting 1956-57, 1957-58). Wavy, fragmented slip lines are seen when incoherent, large nondeforming particles are encountered during the movement of glide dislocations (Wilcox and Gilbert 1967; Greetham and Honeycombe 1960-61; Price and Kelly 1962). Starke et al (1973) have shown that small germanium clusters can be sheared. As the slip traces in partially-aged condition used in this work are similar to those obtained on peak-hardened condition (Kishore and Vasu 1978) and the longer and somewhat widely spaced rods of peak-aged state have been shown to be sheared by moving dislocation using TEM (Kishore et al 1976), it may be inferred that in the present underaged condition also the precipitate particles are cut through by the glide dislocations. Further evidence to this deduction comes from an examination of $\tau-T^{2 / 3}$ relation following the report of Chun and Byrne (1969). They examined the strengthening in a $\mathrm{Mg}-5 \% \mathrm{Zn}$ alloy by determining the temperature dependence of CRSs for the as quenched, fully-hardened and overaged conditions. The shearing of the precipitates in the peak aged state, and the linear variation of flow stress, $\tau$ with $T^{2 / 3}$ were noticed by them. Lipsitt (1971) also showed that yield strength in the Al-Zn alloy varies linearly with $T^{2 / 3}$. In figure 5 are plotted the data showing variation of flow stress with $T^{2 / 3}$ for the under-aged Al-Ge alloy. For the sake of comparison the results obtained in the peakaged state are also included. It is noteworthy that the points lie on a straight line in both the cases suggesting the existence of similar interaction between the glide dislocations and the precipitate particles. Hence, it may be inferred that as in the peak-hardened 


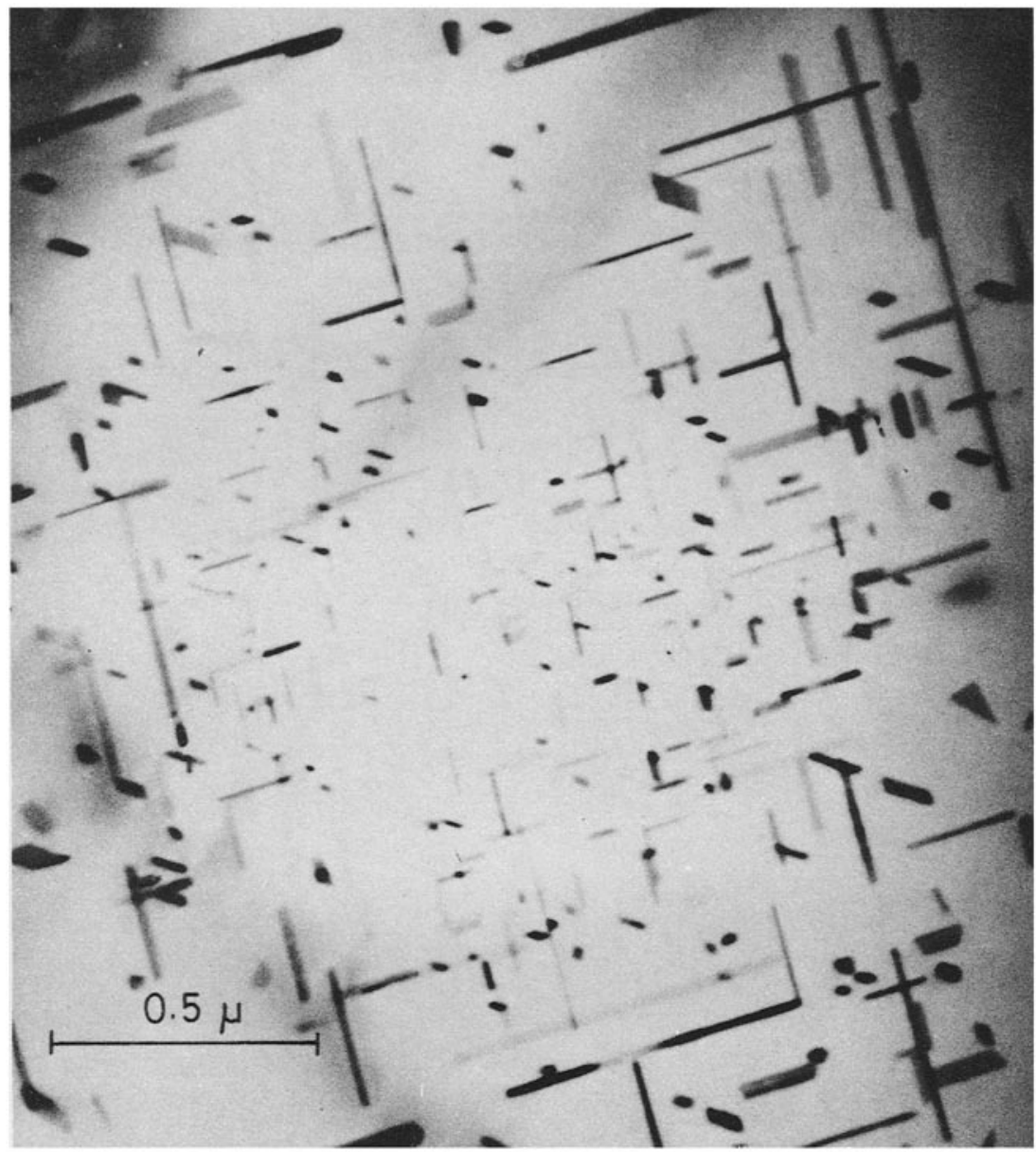

Figure 3. A TEM photograph of the peak-hardened alloy $\left(70 \mathrm{hr}\right.$ at $\left.165^{\circ} \mathrm{C}\right)$ showing rod-, triangular-, and rectangular-shaped precipitates.

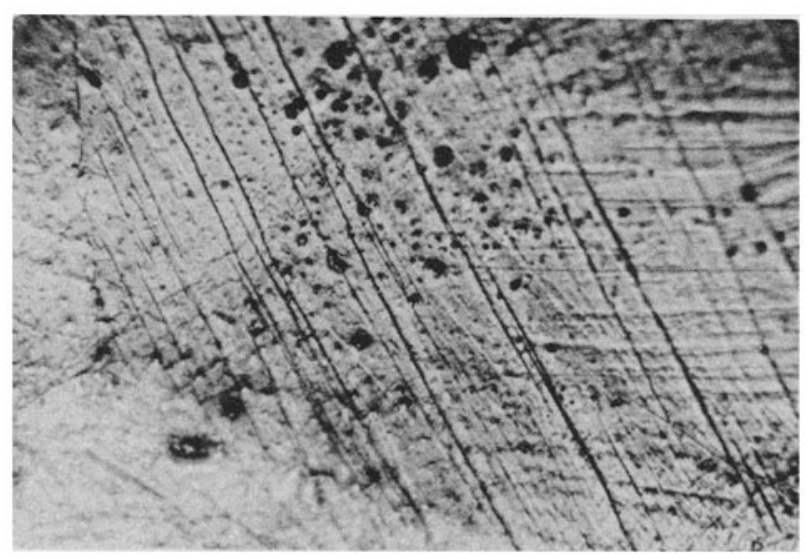

Figure 4. Slip traces in under-aged sample deformed at room temperature $(\varepsilon=25 \% ; 200 x)$. 

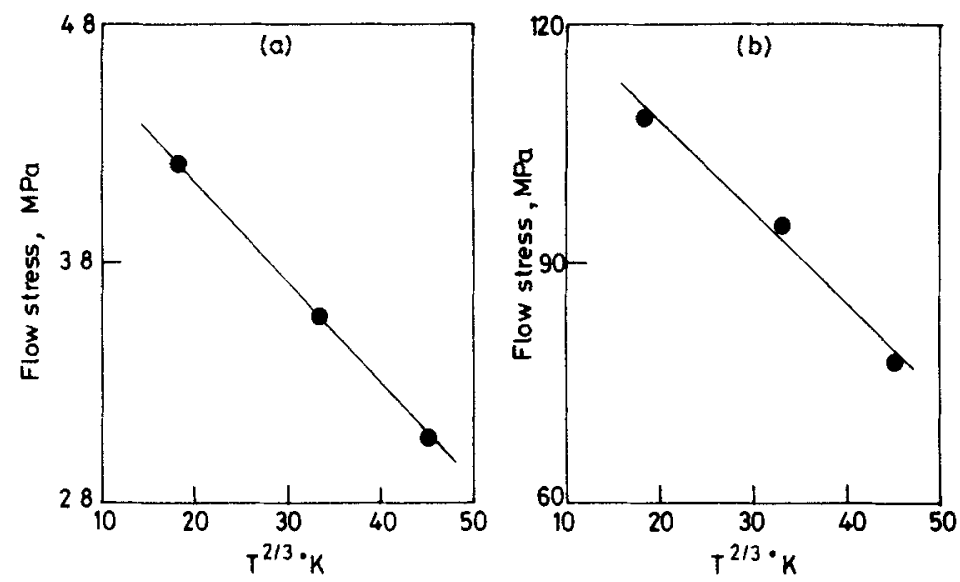

Figure 5. Flow stress-(temperature $)^{2 / 3}$ relation for (a). under-aged (b). peak-aged conditions $\left(\dot{\varepsilon}=9.8 \times 10^{-4} \sec ^{-1}\right)$.

state, in the under-aged state too, the dislocations penetrate the germanium precipitates.

In view of the similarity of behaviour of flow stress variation with temperature as well as nature of slip traces in the under-aged condition with peak-aged alloy reported earlier (Kishore and Vasu 1978) it can be said that in the partially-aged condition also the Ge precipitates are sheared by the glide dislocations.

\section{Conclusions}

Partially-aged alloy exhibit straight slip traces. The flow stress of the dilute alloy varies linearly with $T^{2 / 3}$ and the moving dislocations cut through the germanium precipitates.

\section{Acknowledgements}

The author thanks Prof. K I Vasu for his interest in the work. The assistance received from colleagues in the Department is gratefully acknowledged.

\section{References}

Chun J C and Byrne J G 1969 J. Mater. Sci. 4861

Greetham G and Honeycombe R W K 1960-61 J. Inst. Metals 8913

Kelly A 1963 in Electron microscopy and strength of crystals (eds) G Thomas and J Washburn (New York: Interscience) p. 947

Kishore, Sastry D H and Vasu K I 1976 Proc. Second Int. Conf. on Mechanical Behaviour of Materials, Boston, USA 1851

Kishore and Vasu K I 1978 Metallography 1151

Lipsitt H A 1971 Metall. Trans. 21739

Lutzering G and Weissman S 1970 Acta Metall. 18785

Mott N F and Nabarro F R N 1940 Proc. Phys. Soc. 5286

Nicholson R B and Nutting J 1961 Acta Metall. 9332

Nourbakhsh S and Nutting J 1980 Acta Metall. 28357 
Prasad Y V R K, Sastry D H and Vasu K I 1969 J. Indian Inst. Sci. 51377

Price R J and Kelly A 1962 Acta Metall. 10980

Raynor D and Silcock J M 1970 Metal Sci. J.4 121

Seeger A 1963a J. Phys. Soc. Jpn 18 p. 59

Seeger A 1963b Proc. at NPL, Vol I Symp. No. 15 The relation between structure and mechanical properties of metals 4

Silcock J M 1960 Acta Metall. 8589

Starke E A, Kralik G and Gerold V 1973 Mater. Sci. Eng. 11319

Thomas G and Nutting J 1956-57 J. Inst. Metals 851

Thomas $G$ and Nutting J 1957-58 J. Inst. Metals 868

Wilcox B A and Gilbert A 1967 Azta Metall. 15601 